* Especialista em Gestão Pública pela Universidade Estadual do Rio Grande do Sul (2015). Mestre em Letras pela Universidade Federal do Rio Grande do Sul. Bacharel em Ciências Jurídica e Sociais pela Universidade do Vale do Rio dos Sinos (2001). Licenciada em Letras, português, pela Universidade do Vale do Rio dos Sinos (1992). E-mail: patrícia.seger@yahoo.com.br

** Doutor em Recursos Hídricos e Saneamento Ambiental no Instituto de Pesquisas Hidráulicas da UFRGS. Professor Adjunto da Universidade Estadual do Rio Grande do Sul. Mestre em Direito pela Universidade de Caxias do Sul (2002). Especialista em direito e em educação. Graduação em Ciências Jurídicas e Sociais pela Universidade Federal do Rio Grande do

\section{O PAPEl da LeI de IMprobidade Administrativa para a Minimização de CONDUTAS INEFICIENTES}

BRAZILIAN IMPROBITY ADMINISTRATIVE LAW'S Role IN Minimizing INEFFICIENTE BEHAVIOR

\section{Patrícia Maria Seger de Camargo* Celmar Corrêa de Oliveira**}

Como citar: CAMARGO, Patrícia Maria Seger de; OLIVEIRA, Celmar Corrêa. O papel da lei de improbidade administrativa para a minimização de condutas ineficientes. Revista do Direito Público, Londrina, v. 13, n. 1, p. 42-69, abr. 2018. DOI: 10.5433/1980-511X2018v13n1p42. ISSN: 1980-511X.

Resumo: A Administração Pública precisa de valores éticos e de instrumentos jurídicos que previnam ou minimizem erros administrativos inescusáveis. A presente pesquisa fundamentase na Lei de Improbidade Administrativa brasileira e visa diagnosticar condutas de agentes públicos responsabilizados por improbidade administrativa culposa, bem como analisar como a Lei de Improbidade Administrativa brasileira pode contribuir para minimizar condutas ineficientes. O trabalho apresenta uma análise estrutural da Lei de Improbidade Administrativa brasileira e verifica quais condutas previstas no diploma legal admitem forma culposa. Na sequência apresenta condutas 
coletadas em julgados do Tribunal de Justiça do Estado do Rio Grande do Sul, no período compreendido entre 01/01/2010 e 19/12/2015, responsabilizadas por ação ou omissão culposa. $\mathrm{Na}$ análise de resultados, identifica as causas dessas condutas culposas. A abordagem da pesquisa é qualitativa, e o material utilizado são fontes indiretas. Nas conclusões, a pesquisa permitiu identificar o ponto de fraqueza que atinge a eficiência funcional e apresenta de que modo a Lei 8.429/92 explicita funcionalidades preventivas, assumindo função de ferramenta jurídica educativa no campo ético normativo.

Palavras-chaves: Direito. Improbidade. Culpa. Erário. Ineficiência.

Abstract: Public Administration needs ethical values and legal instruments in order to prevent or minimize inexcusable administrative errors. Furthermore, this research analyzes the Brazilian Administrative Misconduct Act and aims at diagnosing public officials' conduct liable for culpable administrative impropriety and analyzing how the Brazilian Administrative Misconduct Act can help minimize inefficient behavior. The paper presents a structural analysis of the Brazilian Administrative Misconduct Act and verifies which conducts in the statute allow for culpable behavior. Next, this study presents actions and behaviors collected in cases, judged in the Court of Justice of Rio Grande do Sul State, in the period between 01/01/2010 and $12 / 19 / 2015$, held accountable for culpable
Sul. E-mail: celmaroliv@ gmail.com 
action or omission. An analysis identifies the causes of culpable actions. This research has a qualitative approach and the material utilized is from indirect sources. Finally, this study identified a weak point affecting the operational efficiency of the public administration and presents the theory of how the $8.429 / 92$ act clearly exhibits possible preventive functionalities, undertaking the function of an educative law tool in the normative ethics field.

Keywords: Law. Malpractice. Guilt. Exchequer. Inefficiency. 


\section{INTRODUÇÃO}

O doutrinador italiano Matarella (2012) alude que políticas públicas e setores administrativos têm de lidar com os riscos de erros profissionais e a necessidade de prevenção. Afirma o autor que a prevenção na esfera administrativa deve ser feita em várias frentes, porque existem muitos pontos fracos que permitem o deslizamento de negligências. Dentre os remédios existentes no sentido de prevenir condutas deste tipo, o autor menciona os códigos de conduta para os políticos e para as categorias de trabalhadores.

No Brasil, o código geral de condutas dos agentes públicos (OSÓRIO, 2013), aí incluídos políticos e trabalhadores do setor público, é a Lei de Improbidade Administrativa (LIA), Lei Federal 8.429. (BRASIL, 1992).

Tal diploma regulamentou o art. 37, $\S 4^{\circ}$, da Constituição Federal de 1988 (BRASIL, 1988), que estabeleceu o poder punitivo do Estado por meio do regime de sujeição geral, ${ }^{1}$ fixando responsabilidades concretas no âmbito do direito administrativo sancionador para a repressão de condutas que violem o dever de probidade administrativa. Consequentemente, o poder punitivo aos atos de improbidade administrativa ficou a cargo do Judiciário, a partir do ramo do direito administrativo sancionador. Constituinte e legislador, através da LIA brasileira, separaram o ramo do direito administrativo sancionador do processo administrativo, redimensionando a sanção administrativa não somente ao poder administrativo disciplinar, mas situando-a também no processo judicial

1 Explica Simão Neto que o poder de punir considera a submissão dos cidadãos a um ser soberano, fruto da própria ideia de Estado. É a situação em que se encontra toda e qualquer pessoa, independentemente de possuir vínculo particular com a Administração Pública. O jus puniendi é materializado pelo Judiciário e o bem tutelado não é mais o serviço interno da Administração, mas valores externos a ele que acarretam interesse a toda a sociedade. 
em ramo específico, em face da sujeição geral a que toda e qualquer pessoa está submetida. (SIMÃO NETO, 2014).

A LIA, ao regulamentar o dispositivo constitucional, estabeleceu condutas objetivas, que, praticadas subjetivamente com dolo ou culpa, deverão ser punidas a partir do devido processo judicial (BRASIL, 1992). Assim, previu a possibilidade de punição por determinadas práticas culposas, as quais são desencadeadas por condutas negligentes, imprudentes ou imperitas ${ }^{2}$ e que, portanto, são praticadas com a violação do dever de diligência, que deve ser observado no campo da ética pública. A Lei 8.429/92, ao assim determinar, ultrapassou a regulamentação de sanções a condutas desonestas, sancionando também as graves ineficiências funcionais. (OSÓRIO, 2013).

Faz-se relevante dizer que o conceito de eficiência funcional não requer avaliação somente de resultados, porquanto "o dever ético de eficiência funcional não representa somente a ambição por concretos e pragmáticos resultados políticos e econômicos". (OSÓRIO, 2013, p. 59). ${ }^{3}$ A valoração da eficiência funcional considera também os parâmetros éticos do agir administrativo, releva das ações, das omissões e dos resultados. Portanto, tais parâmetros éticos integram o conjunto de resultados.

Nessa esteira, há uma avaliação do percurso do agir até o resultado, o conjunto desse percurso compondo o conceito de eficiência funcional.

Considerando esse conceito de eficiência funcional no setor

2 No art. 18, inciso II do Código Penal brasileiro (BRASIL, [2018?]), encontra-se a seguinte definição de tipo culposo: "Diz-se do crime: culposo, quando o agente deu causa ao resultado por imprudência, negligência ou imperícia".

3 O autor explica a linha adotada no discurso do italiano administrativista Sabino Cassese, que põe ênfase na necessidade de controle tanto da ineficiência quanto da desonestidade, combinando o conceito de eficiência com os parâmetros ético-normativos da conduta pública, de modo a não permitir a consumação ou legitimação de condutas economicamente úteis e eticamente nocivas à sociedade. 
público, o presente trabalho visa diagnosticar fraquezas que determinam ineficiências funcionais e analisar como a LIA brasileira pode auxiliar na prevenção e mitigação de tais ineficiências.

O objetivo geral da pesquisa é identificar as fraquezas que deram origem às condutas culposas de agentes e analisar aspectos funcionais e estruturais da Lei 8.429/92 que orientem o modo de contribuição para a minimização de condutas ineficientes do setor público. Para tanto, são objetivos específicos: apresentar a estrutura e funcionamento da LIA; verificar as condutas previstas pelo diploma legal sob a forma culposa; levantar condutas culposas em ações de improbidade administrativa julgadas pelo Tribunal de Justiça do Estado do Rio Grande do Sul (TJRS); identificar as causas que determinaram a responsabilização culposa; trazer à tona as fragilidades que determinaram a responsabilização dos agentes públicos por condutas ineficientes; analisar de que forma a LIA contribui para a prevenção e minimização de ineficiências funcionais.

Embora a pesquisa seja efetuada a partir da aplicação da LIA na sua vertente punitiva, a justificativa para seu desenvolvimento está no interesse de identificar formas de auxiliar o planejamento e o controle de condutas inadequadas no campo da ética pública, que possam prevenir e mitigar as indesculpáveis ineficiências funcionais na Administração Pública.

\section{MÉTODOS E MATERIAIS}

A presente pesquisa tem por escopo diagnosticar fragilidades em ações praticadas por agentes públicos relacionadas a escolhas éticas no exercício de suas atividades funcionais que resultaram, independentemente da intenção volitiva dos mesmos, na má administração pública. O 
diagnóstico foi realizado a partir da aplicação da LIA em processos judiciais, consideradas tão somente as responsabilizações por condutas culposas, haja vista que essas estão diretamente relacionadas à eficiência funcional.

Foram analisados os conteúdos de acórdãos judiciais proferidos pelo TJRS que deram provimento a Recursos de Apelação para condenar, ainda que parcialmente, os agentes processados por atos de improbidade administrativa culposa.

Considerando que a pesquisa não visa quantificar dados, mas apenas explorar aqueles encontrados por meio da análise de conteúdo, o procedimento metodológico adotado foi o qualitativo.

Para o levantamento de condutas consideradas culposas pelo TJRS, foram pesquisados acórdãos sob o argumento "improbidade administrativa culposa" prolatados no período entre 01/01/2010 e 19/12/2015. Optou-se por restringir a busca ao período dos últimos cinco anos pela necessidade de delimitar um número de documentos a serem analisados, haja vista a extensão desses. Considerando o período delimitado e o argumento de pesquisa selecionado, foram localizados 71 acórdãos cíveis. O site do TJRS ${ }^{4}$ (c2010) foi acessado no dia 19/12/2015 às $13 \mathrm{~h} 30 \mathrm{~min}$.

Dos 71 documentos encontrados, foram identificados dez que tratam especificamente de responsabilização por danos ao erário em face de conduta culposa. Ainda dentre os 71 acórdãos lidos, os não selecionados foram aqueles que restaram sem condenação por falta de fundamento jurídico ou de provas, ou que não abordaram claramente conduta culposa ou, quando a abordaram, ao final do julgamento, infirmaram a responsabilidade baseada no elemento subjetivo dolo.

4 Disponível em: $<$ www.tjrs.jus.br $>$. 
Ainda é importante mencionar que a pesquisa não pode ser considerada de amostragem quantitativa, porque não quer identificar regularidades dentro de um sistema. Mister que se diga que as condutas previstas na LIA são de tipo aberto, admitindo "enorme quantidade de modelos de condutas proibidas, a partir de processos interpretativos quase infinitos" (OSÓRIO, 2013, p. 209), de modo que a investigação se limita à atitude de encontrar exemplares que, analisados, possam orientar à elaboração do diagnóstico pretendido.

Em face da apresentação prévia do sistema de improbidade administrativa com base em doutrina específica do direito administrativo e de a investigação ser realizada a partir de documentos disponibilizados no site do TJRS, o material utilizado como fonte da pesquisa é todo constituído de documentação indireta.

\section{O SISTEMA DE IMPROBIDADE ADMINISTRATIVA BRASILEIRO}

A Constituição Federal brasileira de 1988 previu ao ilícito de improbidade administrativa sanções normatizadas por um direito administrativo sancionador, que, ao formalizar infrações e sanções extrapenais, protegeu bens jurídicos abrangidos pelo direito administrativo, visando à proteção do dever de probidade administrativa orientado pela moralidade pública. (OSÓRIO, 2013). Constituinte e legislador separaram o ramo do direito administrativo sancionador do processo administrativo, redimensionando sanções não somente ao poder administrativo disciplinar, mas situando-as também no processo judicial em regime de sujeição geral a que toda e qualquer pessoa está submetida. (SIMÃO NETO, 2014). 
Todavia, é importante que se diga que a incidência da LIA não exclui outras responsabilidades decorrentes do ato.

A LIA pode ser definida como um código geral de condutas porque vincula todos os agentes públicos sob responsabilidade pessoal e estabelece condutas gerais abertas, delineando verdadeiros ideais do sistema. Tal código limita a gestão pública, estabelece sanções e limita o jus puniendi do Estado. (OSÓRIO, 2013).

Ainda que para a caracterização de ato de improbidade administrativa seja sempre necessária a participação de um agente público, abrangidas todas as categorias e hierarquias, conforme bem aborda Decoiman (2007), o diploma legal estabeleceu seu alcance a toda e qualquer pessoa que concorrer para a prática de conduta ímproba. (BRASIL, 1992). Nesse sentido, a LIA estende a possibilidade de responsabilidade administrativa e político-administrativa à coparticipação de terceiros relacionados à utilização da coisa pública, estes ficando sujeitos a sanções por ato de improbidade administrativa, ainda que não possuam vínculo formal com a Administração Pública.

Quanto à estruturação e à funcionalidade, a LIA é composta de três grandes blocos normativos de condutas, os quais mantêm constantes relações internas, interligadas por um único sentido. (OSÓRIO, 2013). O primeiro bloco trata de condutas que geram o enriquecimento ilícito art. $9^{\circ}$; o segundo, de condutas que acarretam danos ao erário - art. 10; o terceiro versa sobre condutas violadoras de princípios da Administração Pública - art. 11. (BRASIL, 1992). Cada bloco de condutas expressa rol exemplificativo e não taxativo, o que leva Osório (2013, p.208) a afirmar que a LIA abre espaço para uma "enorme quantidade de modelos de condutas proibidas, a partir de processos interpretativos quase infinitos”. Além disso, conforme explica Osório (2013, p. 384), 
a LIA "perfectibiliza-se a partir de normas sancionadoras em branco", que se integram e a complementam, e não pela sua incidência direta. Diferentes combinações internas como também a complementação da LIA por outras normas perfectibiliza condutas jurídicas ímprobas. Nesse sentido, tentamos representar a estrutura e dinâmica da Lei 8.429/92.

Figura 1 - Sistema de Improbidade Administrativa brasileiro

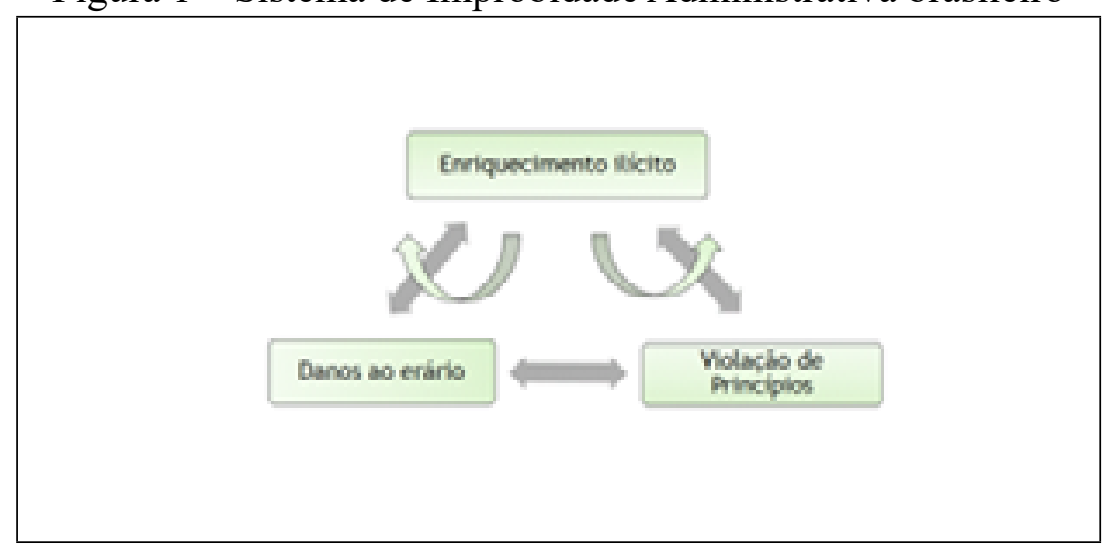

Fonte: Elaborado pelos autores.

A relação interna e constante entre os blocos normativos bem como com outras normas que perfectibilizam a LIA atribuem a esta a condição de um sistema.

Diante desse sistema, as sanções devem ser aplicadas de modo graduado, observado o escalonamento de condutas e a extensão do dano causado, bem como do proveito patrimonial obtido, se houver. Isso porque a LIA enfrenta de forma dinâmica o desafio da tensão entre a segurança jurídica e a efetividade punitiva, jogo que visa evitar discricionariedades interpretativas, banalização da aplicação da Lei e, consequentemente, o aumento da impunidade. Ao passo que o diploma legal abre uma possibilidade de interpretações de condutas violadoras da 
moralidade administrativa, impõe limites e critérios subjetivos a serem observados. (OSÓRIO, 2013).

Com efeito, ao passo que a Constituição Federal de 1988 (BRASIL, 1988) e a LIA (BRASIL, 1992) estabeleceram sanções gravíssimas, tais como a suspensão dos direitos políticos, perda de função pública, indisponibilidade dos bens, ressarcimento ao erário, perda de bens ou valores acrescidos ilicitamente ao patrimônio, pagamento de multa civil e proibição de contratar com o Poder Público ou receber benefícios ou incentivos fiscais ou creditícios, a responsabilidade imposta pela LIA não é de natureza objetiva. Ou seja, não basta ao agente praticar uma conduta tipificada no diploma legal para a comissão de ato de improbidade, haja vista a imprescindibilidade de que à conduta esteja agregado o elemento subjetivo, expresso pelo dolo no caso dos três grandes blocos, sendo admitida também a culpa, no caso do bloco de condutas que trata de danos ao erário.

Nesse diapasão, ao admitir condutas culposas, a LIA estendeu sua incidência não só às desonestidades, mas também às graves ineficiências originadas no campo da ética pública. Por isso, Osório (2013), atribuindo à improbidade administrativa o conceito de modalidade de má-gestão pública, fundamenta que a corrupção é somente uma das faces da improbidade, haja vista que esta abrange também graves e inescusáveis ineficiências, que, reiteradas, acabam por transformar-se em desonestidades e verdadeiros ilícitos.

Também releva dizer que a LIA ultrapassou a proteção à má utilização de recursos públicos, eis que prevê bloco de condutas que atentem contra os princípios da Administração Pública; que constituam ação ou omissão violadora dos deveres de honestidade, imparcialidade, legalidade, e lealdade às instituições, independentemente de ofensa 
ao patrimônio público. Isto é, a proteção foi estendida ao patrimônio imaterial do Estado, à moralidade administrativa em si, à ética pública. A violação de princípios da Administração, desde que preenchidos requisitos objetivos - a conduta - e subjetivos - dolo comprovado - ainda que não resulte em prejuízos patrimoniais à Administração, caracterizará ato de improbidade administrativa.

No caso deste trabalho, a investigação cinge-se à investigação de condutas praticadas sob o elemento subjetivo culpa e, portanto, de condutas que acarretam danos ao erário e que caracterizam ineficiências funcionais.

\section{CONDUTAS CULPOSAS TIPIFICADAS PELA LIA}

Há doutrinadores que consideram impossível a tipificação de conduta culposa pela LIA. Simão Neto (2014, p. 90) assume tal posição ao mencionar que "é impossível pensar em um indivíduo desonesto, corrupto ou devasso da Administração Pública por culpa, assim definida como um ato querido, proveniente de um descuido". Explica ele, neste sentido, que "a doutrina administrativa buscou socorro na doutrina penal e criou um absurdo jurídico ao trazer a classificação da culpa para a LIA, no tocante à culpabilidade do agente, para o campo da tipicidade". (SIMÃO NETO, 2014, p. 91). O autor justifica que a culpa inserida na tipicidade significa ato não intencional. No entanto, a culpa deslocada para a culpabilidade, conforme sistematizado no direito penal, despreza a intenção do agente e parte da avaliação do seu descuido em face do bem jurídico, servindo à avaliação do grau de comprometimento do agente infrator para com o bem jurídico lesado. Sendo assim, Simão Neto (2014) sustenta que o elemento subjetivo do agente ímprobo é sempre o dolo. 
Ferraresi menciona a controvérsia doutrinária sobre a modalidade culposa na LIA, mas sem manifestar sua posição. O autor refere que, "segundo decidiu o Superior Tribunal de Justiça as condutas ímprobas previstas no art. 10 da LIA se satisfazem com o elemento subjetivo culposo, não sendo necessário o dolo". (FERRARESI, 2011, p. 95).

Na concepção de Assunção Neves e Rezende Oliveira (2012, p. 86), "há violação do dever de cautela por parte do agente público e do terceiro, o que justifica, em princípio, a aplicação de sanções”. Esclarecem tais autores que, na medida em que o Direito Penal estabelece sanções graves, como a restrição de liberdade dos indivíduos, e admite a prática de crimes culposos, não há razão para não se admitir a previsão legal de atos de improbidade na modalidade culposa.

Osório (2013) defende a constitucionalidade dos tipos culposos previstos na LIA, eis que a Constituição Federal de 1988 não restringiu a improbidade culposa. Aduz o autor que, contrariamente, a Constituição reforça a proteção dos valores de eficiência ao abrigo da moral administrativa e de princípios expressos nos art. 37 ou 70. E é com base nesta constitucionalidade da improbidade culposa que o autor afirma que, na perspectiva conceitual, improbidade não se confunde com desonestidade, sendo que outras condutas não dolosas também podem ser catalogadas como ímprobas - razão pela qual afirma que a corrupção é tão somente uma das faces da improbidade, mas não a única, porque há outras condutas que conformam a má administração pública e que se ajustam à improbidade administrativa. Refere-se, nesse sentido, às graves ineficiências funcionais.

O que é consenso entre os autores é que a interpretação da legislação de improbidade deve ser feita à luz dos princípios da proporcionalidade e da razoabilidade, tanto na tipificação de condutas 
como na aplicação das sanções. Nesse sentido, Osório reforça "que a culpa não se confunde com o erro profissional" (2013, p. 228), o que leva a jurisprudência a afirmar que a LIA não pune o inábil, mas o desonesto. Reafirma que comportamentos culposos merecem valoração compatível às suas peculiaridades, cuja gravidade pode variar e oscilar. Não se trata de defender a quebra do princípio da proporcionalidade ou da razoabilidade nem da quebra da segurança jurídica, alude o autor. Trata-se de valorar adequadamente o elemento culpa tanto na tipificação da conduta como na fixação da pena.

Especificamente sobre o art. 10 da LIA, que trata do bloco de atos exemplificativos antijurídicos que acarretam lesão ao erário, Rizzardo (2014) explica que a improbidade se revela no prejuízo ou desfalque causado ao erário, necessariamente não acarretando benefício ou vantagem ao agente, embora possa reverter em benefício de terceiros. A lesão que causa perda patrimonial é causada por condutas como malversação, desperdício, indevida aplicação, apropriação de bens e valores, dissipação, destruição e demolição. $\mathrm{O}$ ato pode ser voluntário, dirigido para lesar, desonesto, doloso. Entretanto, também pode ser culposo, caracterizado pelo desleixo, pela falta de cuidado, por negligência no cumprimento das obrigações ou por descontrole administrativo. Esclarece ainda o autor que o art. 10 da LIA enumera uma série de hipóteses, permitindo a eventualidade de outras existirem. A má destinação de recursos públicos, o desvio de patrimônio, apropriação indevida, desperdício, alteração da destinação de valores e de bens, dilapidação de haveres, utilização para benefício próprio, extravio de bens ou abandono do patrimônio de modo a propiciar a deterioração ou furto, falta de providências para a conservação, omissão de medidas de preservação ou de satisfação de créditos, venda com prejuízos, gasto mal 
feito, esbanjamento de bens e dinheiro, sucateamento, abandono de obras inconclusas e contratação desnecessária de servidores são exemplos de modos de causar lesão ao erário.

Duas observações devem ser ressaltadas antes de se passar à próxima seção, cujo quadro apresenta exemplos de condutas culposas encontradas no site do TJRS dentre seus julgados. A primeira observação é que as condutas culposas previstas na LIA podem ser do tipo omissivo ou comissivo, e a definição da culpa decorre de atos negligentes, imprudentes ou imperitos do agente. A segunda é que tais condutas, necessariamente, devem causar prejuízo ao erário.

\section{RESULTADOS}

Conforme já mencionado, foram selecionados e lidos 71 acórdãos de julgamentos do TJRS, disponíveis no site do órgão do Judiciário para consultas. ${ }^{5}$ Desses, 10 preencheram as condições de busca: condutas culposas do tipo comissiva ou omissiva que, fundadas em ineficiências funcionais, resultaram em prejuízo ao erário público.

Os achados foram sintetizados no quadro a seguir, que apresenta registros na seguinte ordem: número do acórdão no TJRS; data do julgamento do recurso pelo TJRS; a Comarca de origem; o tipo de conduta: comissiva ou omissiva; o fundamento da conduta culposa, que significa a motivação da mesma; o agente culposo, com especificação da categoria: se agente público político, servidor ou terceiro.

\section{Quadro 1 - Síntese de condutas culposas TJRS}

5 TJRS, c2010. 


\begin{tabular}{|c|c|c|c|}
\hline $\begin{array}{l}\text { Número de } \\
\text { acórdãos }\end{array}$ & Interregno & Fundamentos da culpa & Agentes \\
\hline 10 & $\begin{array}{c}01 / 01 / 2010 \\
a \\
19 / 12 / 2015\end{array}$ & $\begin{array}{ll}\text { - } & \text { negligência na gestão } \\
\text { - } & \text { culpa in eligendo } \\
\text { - } & \text { ausência de cautela } \\
\text { - } & \text { desídia } \\
\text { - } & \text { inobservância dos } \\
& \text { princípios da AP } \\
\text { - } & \text { negligência/imperícia } \\
\text { - } & \text { irresponsabilidade na } \\
\text { - } & \text { gerência administrativa } \\
& \text { negligência na verificação } \\
\text { - } & \text { negligência de fiscalização } \\
\text { - } & \text { falta de controle nas } \\
& \text { operações }\end{array}$ & $\begin{array}{l}\begin{array}{l}\text { Agentes públicos: } \\
\qquad \quad \text { Políticos } \\
\bullet \quad \text { Servidores }\end{array} \\
\text { Autônomo } \\
\text { credenciado à AP } \\
\text { Diretores de } \\
\text { sociedade de } \\
\text { economia mista } \\
\text { Terceiro não } \\
\text { vinculado à AP }\end{array}$ \\
\hline
\end{tabular}

Fonte: Elaborado pelos autores.

Nota: Utilizou-se a sigla AP para Administração Pública.

O período de buscas foi delimitado entre 01/01/2010 e 19/12/2015. Dos dez acórdãos selecionados, ${ }^{6}$ observa-se ocorrência de julgamentos de condutas culposas nos anos de 2011, 2012, 2013 e 2015. Dentre os julgamentos ocorridos em 2010 e 2012 sob o argumento de pesquisa: a) não foram registrados julgamentos de improbidade administrativa por conduta culposa; ou b) não houve condenação pela falta de prova da conduta culposa ou do efetivo prejuízo ao erário, ou c) no desenrolar do julgamento a conduta foi considerada dolosa.

Os dez acórdãos selecionados referem-se a diferentes Comarcas do Estado: General Câmara, Bom Jesus, Esteio, Panambi (município de Condor), Santo Ângelo (município de Eugênio de Castro), Porto

6 Rio Grande do Sul (2015, 2014, 2013a, 2013b, 2013c, 2012a, 2012b, 2011a, 2011b, 2011c). 
Alegre, Palmeira das Missões, Gramado, Cruz Alta e São Lourenço do Sul, respeitada a ordem cronológica de julgamento.

Considerados os agentes responsabilizados pelas condutas, foram registrados: a) agentes políticos: prefeitos municipais e secretários municipais; b) servidores da Administração direta; c) profissional autônomo credenciado (vinculado) à Administração Pública; d) diretorespresidentes de sociedade de economia mista; e) terceiro beneficiado, não vinculado diretamente à Administração Pública.

Das condutas culposas encontradas, cinco foram consideradas por omissão dos agentes e cinco por comissão de atos. Das causas que justificaram as condutas praticadas por omissão ou comissão, foram registradas: negligência na gestão da coisa pública, culpa in eligendo, ausência de devida cautela, culpa grave, omissão injustificável, desídia para com a coisa pública, inobservância dos princípios da Administração Pública, em especial o da legalidade, negligência no trato da coisa pública, irresponsabilidade na gerência administrativa, ausência de cautelas, negligência/imperícia, negligência na verificação de hipóteses legais, negligência do dever de ofício de fiscalização, falta de controle nas operações, imprudência e imperícia.

A soma dos prejuízos aos cofres públicos, em face de ineficiência funcional em dez diferentes municípios do Estado equivale a $\mathrm{R} \$$ $773.641,65$.

\section{ANÁLISE DOS RESULTADOS E IDENTIFICAÇÃO DE PONTOS DE FRAQUEZA QUE LEVARAM ÀS CONDUTAS INEFICIENTES}

Da análise das condutas comissivas e omissivas culposas extrai-se 
como causas marcantes a negligência, a imprudência e a imperícia dos agentes.

A ausência de devida cautela, omissão injustificável, desídia para com a coisa pública, inobservância dos princípios da Administração Pública, em especial o da legalidade, irresponsabilidade na gerência administrativa e a falta de controle nas operações são desdobramentos dessas três causas das condutas culposas.

Nesse sentido, tanto a negligência quanto a imprudência ou a imperícia dos agentes públicos evidenciam a falta de comprometimento ético, porque todas denunciam a ausência de um comportamento leal e responsável, necessário ao atingimento de bons resultados: o cuidado e a atenção, a precaução e a consideração de um conhecimento técnico mínimo.

Nesse diapasão, o ponto de fragilidade que parece se sobressair dessa falta de cuidados, inoperância, más escolhas, falta de gerenciamento, mau gerenciamento, desconhecimento inescusável e tantas outras falhas não intencionais é a falta de responsabilidade, derivada de um despreparo para os deveres do exercício da função pública, que deveriam abranger a capacidade de efetivamente distinguir as peculiaridades dos deveres públicos dos deveres privados das pessoas, a partir de um campo ético público específico.

Osório (2013), sobre a temática da ética, alude a uma disciplina de responsabilidade aplicada à função pública, com eixo básico na ideia de bem comum e de pessoas a serviço de interesses gerais dentro do Estado. Defende ele que a ética é a disciplina normativa da atuação dos servidores orientados a satisfazer interesses gerais da comunidade disciplina especializada e restrita, que supõe responsabilidade jurídica, formando o campo da ética pública das responsabilidades. Trata-se do 
despreparo no campo da ética pública caminhando ao lado da legalidade.

Nesse sentido, demonstra o autor que os organismos internacionais têm adotado posturas comprometidas com soluções que ultrapassam o viés da corrupção administrativa para abarcar fenômenos complexos de efeitos devastadores, que não podem situar-se num marco de menor importância, como é o caso do Código Internacional de Conduta para titulares de cargos públicos, elaborado pelas Nações Unidas e que estabelece que os titulares de cargos públicos sejam leais aos interesses públicos de seu país, tal como se expressem por meio das instituições democráticas de governo, de maneira eficiente e eficaz.

Os deveres genéricos de diligência, justiça e imparcialidade requerem um olhar que ultrapasse as desonestidades corruptas ou corruptoras, a fim de abranger comportamentos que, mesmo não intencionais, violem obrigações e deveres que deveriam ser sempre observados. Osório (2013) aduz que há toda uma tendência de alargamento de estruturas estatais em busca da repressão de múltiplas modalidades de atos ilícitos, quer na forma de desonestidades, quer na forma de ineficiências intoleráveis.

\section{A FORMA COMO A LIA ATUA PARA A MITIGAÇÃO DE CONDUTAS INEFICIENTES NO SETOR PÚBLICO}

Nesse cenário retratado, a LIA adquire papel vanguardista a partir da renovação do sistema punitivo constitucional, apresentando elementos que orientam à maior eficácia em face das ferramentas que disponibiliza.

A Lei brasileira organizada na forma de um sistema operacionalizado por um código geral normatiza ideais desse sistema, eis que assume o papel de referência geral para todos os agentes públicos, de 
todas as categorias e hierarquias e instituições públicas, ao mesmo tempo em que não afasta a incidência de leis específicas de categorias setoriais. (OSÓRIO, 2013). Como referência geral, a Lei cria um espaço de autodisciplina no campo ético, servindo como ferramenta educativa aos agentes públicos no exercício de suas atividades. A LIA, nesse sentido, estabelece pautas de conduções éticas públicas gerais para a proteção dos bens e dos interesses públicos, exercendo um caráter preventivo a transgressões, que orienta o agir dos agentes públicos no campo da moralidade administrativa. Com isso, oferece a possibilidade educativa de atitudes conscientes preventivas a transgressões ao sistema, ainda que por meio de regras de proibição. Ao passo que fixa tipos abstratos abertos, fixa a intenção de igualdade e de responsabilidade, preservando um núcleo básico de orientação para as ações de responsabilidade dos agentes públicos.

Esses ideais gerais do sistema incidem sobre todos os agentes públicos, indiferentemente das categorias e hierarquias, a uns orientando em maior escala os limites a decisões discricionárias e a outros à condução do caminho a seguir, com observância da lei no desempenho de suas funções. É pela condição de código geral que a LIA se revela um instrumento a ser explorado para a tutela da probidade administrativa, proporcionando controle no exercício das atividades públicas.

$\mathrm{Na}$ forma de código geral de condutas, a LIA estabelece a todo o setor público adesão pela autorregulação e pela autovinculação, a partir do princípio da responsabilidade pessoal (OSÓRIO, 2013). Nessa esteira materializa-se como instrumento educativo, a serviço da diminuição de riscos no percurso de decisões no campo da ética pública a todos os operadores públicos.

Ainda como código geral de condutas, a LIA fixa a necessária 
submissão geral, induzindo a autovinculação dos agentes públicos a partir de aspecto pedagógico da autodisciplina. Nos dizeres de Osório sobre autodisciplina e o valor de um código geral:

[...] constitui um intenso estímulo ao fortalecimento de valores éticos em uma organização. [...] fomenta o fortalecimento moral do indivíduo e sua adesão espontânea a valores republicanos e democráticos, o que constitui principal ferramenta preventiva de ilícitos e desvios. [...]. Daí o caráter positivo do Código Geral, bem como sua vocação sociopolíticoreformadora e transformacional, gerando efeitos na consolidação de uma ética republicana no setor público. (2013, p. 180, 183).

Nesse aspecto, a LIA serve como ferramenta que aproxima a ética do jurídico, resultando na orientação do agir dos agentes públicos e na prevenção de transgressões ao sistema que levem a resultados ineficientes. Ela se presta para punir, mas também para guiar escolhas em um percurso ético normativo até o resultado eficiente, que releva da legalidade ao lado da moralidade.

A LIA significa o marco da autodisciplina institucional (OSÓRIO, 2013), é lei geral que, ao mesmo tempo, limita e orienta a atuação dos agentes públicos, conduzindo-os a uma postura de autorresponsabilidade e compromisso pessoal com os interesses da população. Ela significa a universalização do princípio da responsabilidade pelo dever ético jurídico.

Ao prever proibições a condutas ineficientes sob modalidade culposa, há um reforço da Lei pela vertente educativa. É de se ressaltar 
que o componente subjetivo culpa também serve ao controle de ações e omissões negligentes. Quanto a esse aspecto, a LIA materializa-se como controle de atitudes diligentes, consolidando-se como verdadeira ferramenta a ser explorada para a melhor preparação ao exercício de deveres públicos no campo da ética pública jurídica.

Em face disso é que Rizzardo (2014, p. 370) afirma que "o diploma (LIA) representa a conscientização dos deveres cívicos em relação ao patrimônio público [...]"'.

Extrai-se, portanto, que a Lei 8.429/92 pode auxiliar na mitigação de condutas investigadas neste trabalho não somente pela vertente repressiva, mas também pela força preventiva que oferece na forma de ferramenta educativa, a ser explorada em disciplina específica voltada à ética jurídica pública.

\section{CONCLUSÃO}

O presente trabalho, com base na LIA brasileira, visou efetuar um levantamento de condutas responsabilizadas com fundamento jurídico em elemento subjetivo culposo, com a finalidade de pontuar as causas que determinaram resultados ineficientes inescusáveis realizados por agentes públicos.

A investigação, partindo da análise de acórdãos de julgamentos de apelações cíveis do TJRS que condenaram diferentes agentes públicos em diversas Comarcas do Estado por improbidade administrativa culposa, permitiu identificar que as causas que geraram condutas ineficientes indesculpáveis tiveram origem em práticas ou omissões negligentes, imprudentes e imperitas dos agentes responsabilizados.

Tais ações ou omissões revelaram a má gestão pública não por 
desonestidades, mas por ineficiências, expondo fraquezas dos agentes públicos de diferentes categorias e hierarquias funcionais no campo da responsabilidade, derivadas da falta de preparo ao exercício dos deveres públicos no campo da ética normativa. Com efeito, as condutas investigadas decorreram não das intenções dos agentes condenados, mas independentemente delas, demonstrando riscos não queridos e não assumidos. Os vetores analisados levaram sempre às ineficiências pela falta de atenção, pela ausência de cautelas e pela falta de conhecimentos mínimos necessários, corroborando o despreparo dos agentes.

De outro lado, o trabalho procurou analisar o sistema de improbidade administrativa brasileiro, partindo da nova estruturação constitucional em 1988, alinhada a preocupações com aspectos jurídicos organizacionais preventivos emanados de órgãos internacionais, que atualmente demonstram preocupação com patologias além da corrupção administrativa. Tal análise foi realizada para o fim específico de verificar como o sistema de improbidade administrativo brasileiro pode atuar para mitigar condutas ineficientes como as investigadas.

Nesse sentido, a análise do sistema de improbidade administrativa brasileiro, operacionalizado pela LIA na forma de um código geral de condutas aos agentes brasileiros, permitiu verificar que a estrutura e a funcionalidade da Lei pátria, além de atuarem na repressão de condutas ineficientes, podem atuar como instrumento pedagógico para a consolidação de uma ética pública normativa preventiva. É pelos seus aspectos de referência geral no campo da ética jurídica que ela vincula todos os agentes públicos, levando-os à autorregulação e à autodisciplina. A sujeição geral pedagógica é reforçada pelo princípio da responsabilidade pessoal, que independe de intenções subjetivas dos agentes, contentando-se com condutas culposas, as quais reforçam o 
olhar a percursos diligentes para alcance de resultados eficientes.

A LIA do Brasil, nesse sentido, apresenta caráter vanguardista, sendo possível constatar sua eficácia não só como ferramenta jurídica na esfera punitiva, mas também na via educativa, como modo de aperfeiçoamento de agentes públicos para cumprimento do dever ético, contribuindo efetivamente para mitigar as indesculpáveis ineficiências funcionais.

\section{REFERÊNCIAS}

BRASIL. Decreto Lei n. 2.848, de 07 de Dezembro de 1940. Código Penal. Disponível em: <http://www.planalto.gov.br/ccivil_03/decretolei/Del2848.htm >. Acesso em: 16 fev. 2018.

. Lei No 8.429, de 2 de junho de 1992. Ementa: Dispõe sobre as sanções aplicáveis aos agentes públicos nos casos de enriquecimento ilícito no exercício de mandato, cargo, emprego ou função na administração pública direta, indireta ou fundacional e dá outras providências. Diário Oficial [da] República Federativa do Brasil, Poder Executivo, Brasília, DF, 03 de junho de 1992, Seção 1, p. 6995. Disponível em: <http://www.planalto.gov.br>. Acesso em: 26 jun. 2016.

. Constituição (1988). Constituição da República Federativa do Brasil. Brasília, DF, Senado, 1988.

DECOIMAN, Pedro Roberto. Improbidade administrativa. São Paulo: Dialética, 2007.

FERRARESI, Eurico. Improbidade administrativa: Lei 8.429/1992 comentada artigo por artigo. Rio de Janeiro: Forense; São Paulo: Método, 2011. 
MATTARELLA, Bernardo Giorgio. Recenti tendenze legislative in materia di prevenzione della corruzione. Giornale di diritto amministrativo, Milano, v. 2, 2012.

NEVES, Daniel Amorim Assumpção; OLIVEIRA, Rafael Carvalho Rezende. Manual de Improbidade Administrativa - direito material e processual. Rio de Janeiro: Forense; São Paulo: Método, 2012.

OSÓRIO, Fábio Medina. Teoria da Improbidade Administrativa: má gestão: corrupção: ineficiência. São Paulo: Editora Revista dos Tribunais, 2013.

RIO GRANDE DO SUL. TRIBUNAL DE JUSTIÇA. ACÓRDÃO DE APELAÇÃO CÍVEL N. 70057984163, $1^{\text {a }}$ CÂMARA CÍVEL, COMARCA DE SÃO LOURENÇO DO SUL. APELANTES: SUCESSÃO DE ROSEMARI LOPES, LUECI JOANA CONTI HUBNER, FLÁVIO LUIZ GOULART, HILMAR HENRIQUE BECKER. APELADO: MINISTÉRIO PÚBLICO. RELATOR: IRINEU MARIANI. PORTO ALEGRE, 04 DE NOVEMBRO DE 2015. DIÁRIO DE JUSTIÇA, 19 NOV. 2015. DISPONÍVEL EM: <HTTP://WWW.TJRS.JUS.BR>. ACESSO EM: 19 DEZ. 2015.

. TRIBUNAL DE JUSTIÇA. ACÓRDÃO DE APELAÇÃO CÍVEL N. 70054294145, $1^{\text {a }}$ CÂMARA CÍVEL, COMARCA DE CRUZ ALTA. APELANTES: PEDRO ALOÍSIO KLOECKNER E OUTROS. RELATOR: CARLOS ROBERTO LOFEGO CANIBAL. PORTO ALEGRE, 11 DE DEZEMBRO DE 2013. DIÁRIO DE JUSTIÇA, 27 JAN. 2014. DISPONÍVEL EM: <HTTP://WWW.TJRS.JUS.BR>. ACESSO EM: 19 DEZ. 2015.

. TRIBUNAL DE JUSTIÇA. ACÓRDÃO DE APELAÇÃO CÍVEL N. 70042516377, DA 2 $2^{a}$ CÂMARA CÍVEL, COMARCA DE GRAMADO. APELANTE: ESPÓLIO DE NELSON 
DINNEBIER. APELADO: MINISTÉRIO PÚBLICO. INTERESSADO: MUNICÍPIO DE GRAMADO. RELATOR: HELENO TREGNAGO SARAIVA. PORTO ALEGRE, 23 DE OUTUBRO DE 2013. DIÁRIO DE JUSTIÇA, 11 NOV. 2013A. DISPONÍVEL EM: <HTTP://WWW.TJRS.JUS.BR>. ACESSO EM: 19 DEZ. 2015.

. TRIBUNAL DE JUSTIÇA. ACÓRDÃO DE APELAÇÃO CÍVELL N. 70052796554, 2a CÂMARA CÍVEL, COMARCA DE PALMEIRA DAS MISSÕES. APELANTES: JOSINO DE TARSO VIDAL TAPIA, ALECRIDES SANT'ANNA DE MORAES, BERNARDINO NUNES MAFALDA E OUTROS. APELADO: MINISTÉRIO PÚBLICO. RELATOR JOÃO BARCELOS DE SOUZA JUNIOR. PORTO ALEGRE, 27 DE MARÇO DE 2013. DIÁRIO DE JUSTIÇA, 08 ABR. 2013B. DISPONÍVEL EM: <HTTP://WWW.TJRS.JUS.BR>. ACESSO EM: 19 DEZ. 2015.

. TRIBUNAL DE JUSTIÇA. ACÓRDÃO DE APELAÇãO CÍVEL N. 70052698743, $3^{\text {a }}$ CÂMARA CÍVEL, COMARCA DE PORTO ALEGRE. APELANTE/APELADO: MINISTÉRIO PÚBLICO. APELANTE/APELADO: INSTITUTO DE PREVIDÊNCIA DO ESTADO DO RIO GRANDE DO SUL. APELANTE/APELADO: PAULO CESAR GONÇALVES BALAGUEZ. RELATOR ROGERIO GESTA LEAL. PORTO ALEGRE, 21 DE MARÇO DE 2013. DIÁRIO DE JUSTIÇA, 01 ABR. 2013C. DISPONÍVEL EM: <HTTP://WWW.TJRS.JUS.BR>. ACESSO EM: 19 DEZ. 2015.

. TRIBUNAL DE JUSTIÇA. ACÓRDÃO DE APELAÇÃO CÍVEL N. 70040377780, DA 2 ${ }^{\mathrm{a}}$ CÂMARA CÍVEL, COMARCA DE SANTO ÂNGELO. APELANTE: ÁLVARO AFONSO DORNELES ROMERO. APELADO: MUNICÍPIO DE EUGÊNIO DE CASTRO. RELATOR: ARNO WERLANG. PORTO ALEGRE, 
07 DE NOVEMBRO DE 2012. DIÁRIO DE JUSTIÇA, 30 NOV. 2012A. DISPONÍVEL EM: <HTTP://WWW.TJRS.JUS.BR>. ACESSO EM: 19 DEZ. 2015.

. TRIBUNAL DE JUSTIÇA. APELAÇÃO CÍVEL N. 70043702471, DA $1^{\text {a }}$ CÂMARA CÍVEL, COMARCA DE PANAMBI. APELANTE/APELADO: JOSÉ FRANCISCO TEIXEIRA CANDIDO. APELANTE/APELADO: MINISTÉRIO PÚBLICO. INTERESSADOS: ÂNGELA MARIA BURGEL E OUTROS. RELATOR: CARLOS ROBERTO LOFEGO CANIBAL. PORTO ALEGRE, 27 DE JUNHO DE 2012. DIÁRIO DE JUSTIÇA, 09 JUL. 2012B. DISPONÍVEL EM: <HTTP://WWW.TJRS.JUS.BR>. ACESSO EM: 19 DEZ. 2015.

. TRIBUNAL DE JUSTIÇA. APELAÇÃO CÍVEL N. 70041269655, DA $1{ }^{\text {a }}$ CÂMARA CÍVEL, COMARCA DE ESTEIO. APELANTE/APELADO: RAMON ALEJANDRO RUIZ VELASCO. RELATOR JORGE MARASCHIN DOS SANTOS. PORTO ALEGRE, 28 DE SETEMBRO DE 2011. DIÁRIO DE JUSTIÇA, 07 OUT. 2011A. DISPONÍVEL EM: <HTTP://WWW.TJRS.JUS. BR>. ACESSO EM: 19 DEZ. 2015.

. TRIBUNAL DE JUSTIÇA. APELAÇÃO CÍVEL N. 70037545472, DA $1^{a}$ CÂMARA CÍVEL, COMARCA DE BOM JESUS. APELANTE: GERALDO SPINELLI GRAZZIOTIN. APELADO: MINISTÉRIO PÚBLICO. RELATOR: JORGE MARASCHIN DOS SANTOS. PORTO ALEGRE, 24 DE AGOSTO DE 2011. DIÁRIO DE JUSTIÇA, 09 SET. 2011B. DISPONÍVEL EM: <HTTP://WWW.TJRS.JUS.BR>. ACESSO EM: 19 DEZ. 2015.

. TRIBUNAL DE JUSTIÇA. APELAÇÃO CÍVEL N. 70030490486, DA $2^{\mathrm{a}}$ CÂMARA CÍVEL, COMARCA DE GENERAL CÂMARA. APELANTE: JOSÉ LUIZ MARTINS NETTO. 
APELADO: MUNICÍPIO DE GENERAL CÂMARA. RELATORA: SANDRA BRISOLARA MEDEIROS. PORTO ALEGRE, 30 DE MARÇO DE 2011. DIÁRIO DE JUSTIÇA, 28 ABR. 2011C. DISPONÍVEL EM: <HTTP://WWW.TJRS.JUS.BR>. ACESSO EM: 19 DEZ. 2015.

. Tribunal de Justiça do Estado do Rio Grande do Sul. Porto Alegre, c2010. Disponível em: <www.tjrs.jus.br>. Acesso em: 19 dez. 2015.

RIZZARDO, Arnaldo. Ação civil pública e ação de improbidade administrativa. Rio de Janeiro: Forense, 2014.

SIMÃO NETO, Calil. Improbidade Administrativa: teoria e prática. Leme: J. H. Mizuno, 2014.

Como citar: CAMARGO, Patrícia Maria Seger de; OLIVEIRA, Celmar Corrêa. O papel da lei de improbidade administrativa para a minimização de condutas ineficientes. Revista do Direito Público, Londrina, v. 13, n. 1, p. 42-69, abr. 2018. DOI: 10.5433/1980-511X2018v13n1p42. ISSN: 1980-511X.

Recebido em: 27/07/2016

Aprovado em: 19/02/2018 